\title{
Comparison of weed control techniques to establish three ground cover species
}

\author{
C.L. Foo, K.C. Harrington and M.B. MacKay \\ Institute of Natural Resources, Massey University, Palmerston North 4442, New Zealand \\ Corresponding author: K.Harrington@massey.ac.nz
}

\begin{abstract}
Weed control strategies for establishing three ground cover species were investigated by planting them in late spring, then assessing eight different control treatments during the following 14 months. The prostrate woody Coprosma acerosa 'Taiko' established best with black weed mat mulch and EcoCover paper mulch, although bark mulches also gave reasonable establishment rates. The brittle succulent, Sedum mexicanum 'Acapulco Gold', also established well with black weed mat and paper mulch, although a sawdust mulch was particularly suitable. The frost-prone Polygonum capitatum, which regrows readily from seed, did best with soil kept bare by hand-hoeing or selective herbicides, although the paper mulch also rated well. Thus the best weed control strategy varied depending on the characteristics of the ground cover being established. Other considerations, including relative costs, are also discussed.
\end{abstract}

Keywords ground cover plants, establishment rate, weed control, herbicides.

\section{INTRODUCTION}

Ornamental ground cover plants can be an effective weed deterrent when fully grown, as their dense foliage prevents new weed seedlings from establishing (Thomas 1977). They can help reduce the labour requirement for weeding of planted sites, and also reduce use of herbicides needed for weed control. However, the establishment phase of ground covers is vulnerable to weed invasion when the ground cover plants are small and have been planted at appropriate spacings, which leaves large gaps in the planting bed between plants.

Ground cover plant species vary in growth form despite all being prostrate species. Coprosma acerosa 'Taiko' is an example of a native lowgrowing woody ground cover with prostrate branches growing from a central stem, but with no rooting occurring from the branches. In contrast, Polygonum capitatum (pink knot-weed) is a trailing perennial herbaceous ground cover plant that produces roots readily along its branches. It also produces numerous pink ball-shaped flower heads that set seed easily, and these are important to enable reestablishment after winter since the plant is frost-tender (Fish 1970; MacKenzie 1997). Sedum mexicanum 'Acapulco Gold' is another prostrate perennial herbaceous ground cover that spreads rapidly. It is a succulent with strong regenerative abilities both from rooted stem nodes and nodal fragments that break off due to its brittle nature (Snodgrass \& Snodgrass 2006).

The objective of this work was to investigate how best to establish ground cover species so that weeds are adequately controlled during the 
initial growth stage. A range of mulch options was compared with selective herbicides and hand-weeding for C. acerosa, P. capitatum and $S$. mexicanum. This follows on from work by Foo et al. (2009) in which establishment of a greater range of ground cover species was investigated but only with sawdust mulch.

\section{MATERIALS AND METHODS}

At a site near Palmerston North, plots of cultivated Manawatu fine sandy loam soil $2 \mathrm{~m}$ by $2 \mathrm{~m}$ were each planted with three plants of either P. capitatum or S. mexicanum, or two plants of C. acerosa, all at $1.0 \mathrm{~m}$ from each other within the plot. Eight weed control strategies were compared for each of the three species. Black polythene weed mat and EcoCover paper mulch were compared with 6-7 cm thick layers of bark nuggets, wood chips and sawdust, and a sixth treatment had 3-4 cm of wood chips on black weed mat. There was also a hand-weeded treatment in which a hand hoe was used every 6-8 weeks to remove weeds, and also a treatment in which selective herbicides were used approximately every 2 months. The herbicides used varied depending on the weed species present. Herbicides applied as spot-applications to weeds in all three ground cover species were (with rates given in brackets as $\mathrm{g}$ ai/10 litres of spray mixture) haloxyfop (3.0) and simazine (50), with other herbicides used in P. capitatum being clopyralid (3.0), tribenuron (0.3) and metsulfuron (0.12), while in $S$. mexicanum, there was use of metsulfuron (0.12), glufosinate (30) and glyphosate (3.6) (shown to be tolerated by Foo et al. 2010). Coprosma acerosa plots also received clopyralid (3.0) and glyphosate (3.6) as required.

The trial was established in late November 2008. Plots treated with bark nuggets and wood chips had $100 \mathrm{~kg} \mathrm{~N} / \mathrm{ha}$ (as sulphate of ammonia) applied prior to laying of the mulch to allow for nitrogen immobilisation, and sawdust plots received $200 \mathrm{~kg} \mathrm{~N} / \mathrm{ha}$. All combinations of ground cover species and weed control strategies were replicated three times using a randomised block design. At planting, the average diameter of ground cover plants was $8.5 \mathrm{~cm}, 25.6 \mathrm{~cm}$ and $33.9 \mathrm{~cm}$ for $S$. mexicanum, $P$. capitatum and $C$. acerosa respectively. Every 2 months the diameter of each ground cover plant was measured, then estimates were made of the percentage ground cover in each plot once the plants grew into each other (as in the case of the P. capitatum). The number of weeds per plot was counted every 2 months, after which they were removed or sprayed in the case of the herbicide treatment. The EcoCover mulch broke down after 6 months, so selective herbicides were used in these plots from then on.

Soil temperature was measured at a depth of $5 \mathrm{~cm}$ under each mulch type (including some freshly laid paper mulch in an area beside the plots) using four temperature sensors per mulch type every 10 minutes between 11 and 25 December 2009, and compared with the temperature at $5 \mathrm{~cm}$ depth for plots with bare soil. Likewise, soil water measurements were made using time-domain reflectrometry (TDR) probes under each mulch type to a depth of $15 \mathrm{~cm}$ and compared with bare soil plots at four positions per treatment once a week for a 5 -week period from December 2009 to January 2010.

All data collected were subjected to an analysis of variance using the GLM procedure in SAS 9.2, and least significant differences were calculated at $\mathrm{P}=0.05$ when significant differences between means were detected.

\section{RESULTS AND DISCUSSION}

As expected, the mulched plots had significantly fewer weeds at each assessment compared to plots with bare soil, as illustrated by the April and October assessments (Tables 1 and 2). Covering the soil with mulch material prevented weed seeds from germinating and establishing. The weeds present in the herbicide plots were sprayed with selective herbicides after each assessment time, although some weed species did survive due to tolerance of the herbicides used. The residual nature of simazine resulted in few weeds being present at some times of assessment where this herbicide had been used. The decomposition of the EcoCover paper mulch after 6-8 months resulted in more weeds being present in this treatment than other mulch treatments. The 
persistence of the paper mulch in this trial was similar to that found by Harrington \& Bedford (2004). All weeds in mulched treatments were removed after each 2 month assessment, but this took less time than for the hand-weeded plot due to low weed numbers and the ease with which weeds could be pulled from mulches.

For C. acerosa, which roots only from one central point, the plant does not need to contact the soil along its prostrate stems and thus grew best in those mulches that had the least weeds present and no nitrogen immobilisation from decomposition of wood material (Table 1). Thus the black weed mat and the paper mulch resulted in best rates of establishment, while the herbicide treatment resulted in the lowest increase in size, mainly because weeds were not controlled well initially while the most suitable herbicides to use were being determined. It is assumed that growth rates were slow with the sawdust mulch because nitrogen immobilisation was probably greatest with this treatment due to its small particles decomposing more readily than the larger sized bark nuggets and wood chips. Despite more nitrogen fertiliser being used under the sawdust than other treatments to compensate for this, presumably not enough was applied.

Similar results were obtained for the
S. mexicanum in that the black weed mat gave some of the best growth rates, and the herbicides treatment generally gave the poorest establishment. With the herbicides, the effect was partly due to weeds not being well controlled initially, but also apparently due to a check in growth caused by the chemicals used. Sedum mexicanum grows well under warm conditions (Evans 1983), such as provided by black weed mat (Table 3). In addition, the weed mat does not suffer from nitrogen immobilisation like wood-based mulches and provided excellent weed control.

However, unlike the C. acerosa, the most successful treatment for $S$. mexicanum was the sawdust mulch. The friable nature of the sawdust appeared conducive to lateral spreading of the small, rooting stems of the $S$. mexicanum, unlike the bigger chunks of bark for the other woodbased mulches. A disadvantage of the sawdust treatment was that animals such as rabbits were observed to burrow in the sawdust, which adversely affected some of the $S$. mexicanum plants due to their brittle stems. The fragments that did snap off were more likely to re-establish again by rooting into the sawdust compared with the other treatments. Rooting of fragments also occurred well in the plots with bare soil. However,

Table 1 The average diameter $(\mathrm{cm})$ of C. acerosa and S. mexicanum plants in April and October 2009 after being planted in November 2008 with different weed control strategies, and the number of weeds per $4 \mathrm{~m}^{2}$ plot following 2 months of no weeding.

\begin{tabular}{|c|c|c|c|c|c|c|c|c|}
\hline \multirow[b]{3}{*}{ Treatment } & \multicolumn{4}{|c|}{ C. acerosa } & \multicolumn{4}{|c|}{ S. mexicanum } \\
\hline & \multicolumn{2}{|c|}{ Diameter } & \multicolumn{2}{|c|}{ Weeds/plot } & \multicolumn{2}{|c|}{ Diameter } & \multicolumn{2}{|c|}{ Weeds/plot } \\
\hline & Apr. & Oct. & Apr. & Oct. & Apr. & Oct. & Apr. & Oct. \\
\hline Hand-weeding & 57.9 & 72.2 & 46.3 & 33.7 & 32.0 & 60.4 & 38.7 & 36.7 \\
\hline Herbicides & 54.7 & 56.2 & 100.0 & 35.0 & 28.0 & 53.8 & 22.3 & 0.0 \\
\hline Paper mulch & 68.0 & 80.8 & 5.3 & 6.7 & 40.5 & 73.4 & 8.7 & 14.0 \\
\hline Weed mat & 63.2 & 88.7 & 0.7 & 0.0 & 48.1 & 81.4 & 0.0 & 0.0 \\
\hline Weed mat \& chip & 57.8 & 79.1 & 3.7 & 0.7 & 44.6 & 68.1 & 1.0 & 0.3 \\
\hline Wood-chip & 57.7 & 68.2 & 8.7 & 0.3 & 38.4 & 54.4 & 5.0 & 0.0 \\
\hline Bark nuggets & 55.7 & 68.9 & 0.3 & 0.0 & 43.6 & 69.8 & 1.0 & 0.0 \\
\hline Sawdust & 54.2 & 63.6 & 0.3 & 2.0 & 43.5 & 90.1 & 0.7 & 1.7 \\
\hline $\operatorname{LSD}(\mathrm{P}=0.05)$ & 10.8 & 11.8 & 4.0 & 4.2 & 7.8 & 13.0 & 9.6 & 3.8 \\
\hline
\end{tabular}


this method of vegetative spread was undesirable as growth was slower than from normal lateral spread, and damage looked unsightly.

The $P$. capitatum spread much more rapidly than the other two ground cover species following planting, so that it was giving $78 \%$ cover of the plots within 5 months of planting for the best treatment, which once again was the black weed mat (Table 2). The cover of the ground was similar for most other treatments, but growth was a bit less prolific on the large bark nuggets, perhaps because this medium was least conducive for rooting of the stems. The plants seeded prolifically in all plots during the first summer.

The $P$. capitatum plants were unexpectedly susceptible to frost, with the first frosts in April 2009 causing severe damage to the plants, and foliage dying in most plots by the middle of winter. The stems did not die back to the same extent in the bare soil plots of the hand-weeded and herbicide treatments, presumably due to the soil being heated by the sun during the day and releasing this heat at night (as found by others such as Skroch et al. 1992 and O'Connell \& Snyder 1999). Stems lost all leaf material on wood-based mulches, especially the bark nuggets. In Table 3, temperature data for the 5-6 pm period showed soil heating up most in the bare soil and black weed mat plots, and this heat being lost by the 5-6 am measurement period. In the following spring, plants regrew most rapidly from the bare soil plots due to nodes of stems starting to regrow earlier than stems in other treatments. There was also regrowth from seedlings, although only in those media where seedling growth was possible, namely the bare soil plots (hand-weeded and herbicide) and paper mulch, with none in any other treatments.

Although mulches did not help the growth of $P$. capitatum as much as the other two species, Table 3 shows that one advantage of having mulches present is that water is conserved through summer much better than having bare soil. This agrees with other literature such as the work of Rana et al. (2005) who found that black weed mat can give up to $40 \%$ savings in irrigation. The only mulched plot not to have significantly greater soil water than the bare soil was under the sawdust, possibly because the mulches had been laid down for over 12 months by the time these measurements were made and it had decomposed more than the other mulches. Note that the paper mulch, which had completely decomposed after 12 months, was relaid in places to allow these measurements to be made.

An estimate of costs associated with each control strategy has been calculated for $100 \mathrm{~m}^{2}$ of ground cover (Table 3). Estimates of labour costs have been included, being the only component of the hand-weeding $\left(\$ 2444\right.$ per $100 \mathrm{~m}^{2}$ per

Table 2 The average ground coverage (\%) of P. capitatum plants in April and October 2009, and January 2010, after being planted in November 2008 with different weed control strategies, and the average number of weeds per $4 \mathrm{~m}^{2}$ plot following 2 months of no weeding.

\begin{tabular}{lccccrrrr}
\hline & \multicolumn{3}{c}{ \% ground cover } & & \multicolumn{3}{c}{ Weeds/plot } \\
\cline { 2 - 4 } \cline { 7 - 8 } Treatment & Apr. & Oct. & Jan. & & & Apr. & Oct. & Jan. \\
\hline Hand-weeding & 75.0 & 40.0 & 75.0 & & 11.0 & 16.0 & 26.0 \\
Herbicides & 76.7 & 28.3 & 70.0 & & 56.7 & 12.3 & 29.3 \\
Paper mulch & 73.3 & 23.3 & 60.0 & & 0.0 & 3.3 & 23.0 \\
Weed mat & 78.3 & 18.3 & 55.0 & & 0.0 & 0.0 & 0.0 \\
Weed mat \& chip & 75.0 & 10.0 & 18.3 & & 1.3 & 0.3 & 1.0 \\
Wood-chip & 73.3 & 10.0 & 15.0 & & 2.0 & 0.3 & 5.7 \\
Bark nuggets & 68.3 & 20.0 & 11.7 & & 0.0 & 0.0 & 1.0 \\
Sawdust & 73.3 & 11.7 & 26.7 & & 0.3 & 0.0 & 2.3 \\
\hline LSD $(\mathrm{P}=0.05)$ & 4.1 & 11.7 & 9.9 & & 15.0 & 2.0 & 7.4 \\
\hline
\end{tabular}


year), and also a major part of the costs for spotapplication of herbicides (total of $\$ 637$ per 100 $\mathrm{m}^{2}$ per year). For the mulches, an estimate has been included for the labour cost of laying the mulch initially, and for removing the few weeds that established each month. The black weed mat worked out cheapest overall at an estimated annual cost of $\$ 365$ per $100 \mathrm{~m}^{2}$ as little labour was required for weed control and it did not have to be laid $7 \mathrm{~cm}$ deep like the wood-based mulches, which were estimated to cost between $\$ 785$ and $\$ 1348$ per $100 \mathrm{~m}^{2}$ per year. If costs for mulches were extended into a second year, the material cost would not be included for the second year (unless they were topped up) but more labour would be involved as weeds invaded once the material started breaking down.

\section{CONCLUSIONS}

This work has shown that the best weed control strategies for ground cover species vary depending on the type of species being established. Spreading woody ground covers that do not root at the nodes are best established with long-lasting mulch materials, such as black weed mat and bark nuggets, that keep weeds under control for as long as possible.

Brittle succulent ground covers such as $S$. mexicanum can establish well with black weed mat, but to allow growth of the rooted stems and stem fragments, sawdust, paper mulches or soil kept bare by hoeing or herbicides will give best long-term establishment. Although the herbicide treatments did not look good in this work, it was mainly because the best herbicide strategies had not been determined before this trial began. Herbicides do allow bare soil to be maintained more easily than hand-hoeing and is less likely to damage rooted fragments than hoeing. Paper mulch has these advantages as well.

For ground cover species that are susceptible to frost or rely on growth from seeds, bare soil is the best medium for establishment, provided good selective herbicides are available. Use of paper mulch does provide a viable option if selective herbicides are not available, but the ground cover species need to be planted close enough together to allow complete ground coverage before the mulch begins to deteriorate.

\section{ACKNOWLEDGEMENTS}

The authors wish to thank field technicians from the Institute of Natural Resources for assistance with this work, and also Mr Murray Cruickshank for supplying the EcoCover paper mulch used in the trial.

Table 3 The mean soil temperature measured at $5 \mathrm{~cm}$ depth during December 2009, the percentage soil water content measured by TDR to $15 \mathrm{~cm}$ in December to January, and the estimated cost of each treatment for the first year (including labour).

\begin{tabular}{|c|c|c|c|c|c|}
\hline \multirow[b]{2}{*}{ Treatment } & \multicolumn{3}{|c|}{ Mean soil temperature } & \multirow{2}{*}{$\begin{array}{c}\text { Water } \\
\text { content }(\%)\end{array}$} & \multirow{2}{*}{$\begin{array}{c}\text { Cost } \\
\left(\$ / 100 \mathrm{~m}^{2}\right)\end{array}$} \\
\hline & For $24 \mathrm{~h}$ & $5-6 \mathrm{am}$ & $5-6 \mathrm{pm}$ & & \\
\hline Hand-weeding & 20.9 & 15.2 & 26.7 & 28.2 & 2444 \\
\hline Herbicides & - & - & - & - & 637 \\
\hline Paper mulch & 19.5 & 16.8 & 22.8 & 32.4 & 1525 \\
\hline Weed mat & 21.6 & 15.9 & 27.7 & 33.4 & 365 \\
\hline Weedmat \& chip & 20.0 & 17.6 & 22.8 & 33.9 & 785 \\
\hline Wood chip & 19.4 & 17.4 & 21.8 & 35.9 & 1039 \\
\hline Bark nuggets & 18.0 & 17.1 & 19.2 & 33.7 & 1171 \\
\hline Sawdust & 19.2 & 17.8 & 20.9 & 30.7 & 1348 \\
\hline $\operatorname{LSD}(\mathrm{P}=0.05)$ & 0.4 & 0.2 & 0.3 & 2.8 & \\
\hline
\end{tabular}




\section{REFERENCES}

Evans RL 1983. Handbook of cultivated Sedums. Science Reviews Limited, Northwood, Middlesex. 345 p.

Fish M 1970. Ground cover plants $4^{\text {th }}$ ed. David \& Charles Limited, Newton Abbot, UK. 144 p.

Foo CL, Harrington KC, MacKay MB, Wrigley MP 2009. Establishment rate of 12 ornamental ground cover species for weed control. New Zealand Plant Protection 62: 415 (Abstract).

Foo CL, Harrington KC, MacKay MB 2010. Herbicide tolerance of three ornamental ground cover species: Polygonum capitatum, Sedum mexicanum and Soleirolia soleirolii. Proceedings of the $17^{\text {th }}$ Australasian Weeds Conference: in press.

Harrington KC, Bedford TA 2004. Control of weeds by paper mulch in vegetable and trees. New Zealand Plant Protection 57: 37-40.

MacKenzie D S 1997. Perennial ground covers. Timber Press, Portland. 379 p.
O’Connell NV, Snyder RL 1999. Cover crops, mulch lower night temperatures in citrus. California Agriculture 53(5): 37-40.

Rana RS, Yadav SM, Gaur JK, Rathore AS 2005. Comparative performance and evaluation of drip irrigation system with and without application of mulch on ber under arid and semi arid, irrigated regions of Rajasthan. Proceedings of International Conference on Emerging Technologies in Agricultural and Food Engineering. Pp. 278-282.

Skroch WA, Powell MA, Bilderbank TE, Henry PH 1992. Mulches: durability, aesthetic value, weed control, and temperature. Journal of Environmental Horticulture 10(1): 43-45.

Snodgrass EC, Snodgrass LC 2006. Garden roof plants: a resource and planting guide. Timber Press, Portland. 203 p.

Thomas GS 1977. Plants for ground cover (revised). Aldine Press, London. 282 p. 